\title{
Editorial
}

\section{Laser and particle beams prize for outstanding achievements of young scientists in high energy density physics}

The journal Laser and Particle Beams supports young scientists in many different ways. It is the editorial policy to give young scientists a chance to publish their early research work in great detail in a journal with international reputation. Starting this year our journal donates a science prize for young scientists in the field of high energy density physics, which is endowed with $2000 €$. The prize money is meant to enable the prize winner to attend international conferences like the conference on Inertial Fusion Science and Applications (IFSA), which will be held in September this year in Japan (IFSA 2013, Japan), or in the series European Conference on Laser Interaction with Matter (ECLIM), which will be organized in Paris, France in 2014. For the time being, the prize will be awarded during the annual International Workshop on High Energy Density Physics with Intense Ion and Laser Beams, which takes place in January in Hirschegg, Austria.

This year, it was for the $33^{\text {rd }}$ time that scientists from all over the world met at this workshop to discuss high energy density physics, interaction processes of laser and particle beams with matter and inertial fusion science issues. The overall attendance was more than 100 and many young scientists were among the participants.

Academician Professor Dr. Vladimir E. Fortov from the Russian Academy of Sciences served as chairman of the

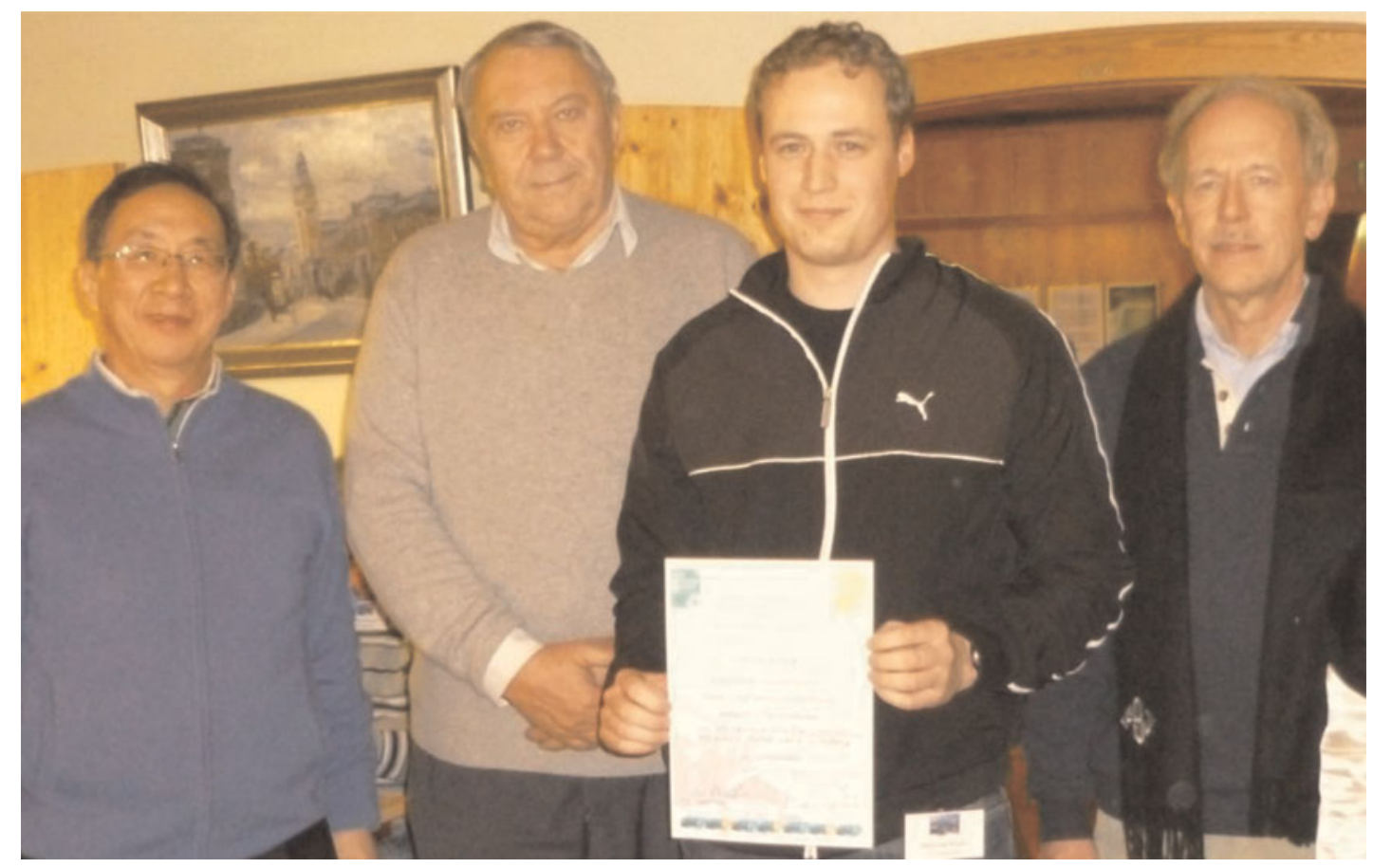

Fig. 1. (Color online) Award Ceremony. From left to right: Professor Dr. H.J. Kong (KAIST, S. Korea), Academician Professor Dr. V.E. Fortov (RAS, Russia), Dr. D. Kraus (TU-Darmstadt, prize winner), Dr. K. Schoenberg (LANL, USA). 
prize selection committee. Due to a large number of excellent contributions the prize was awarded in different categories.

The main prize for a recently finished $\mathrm{PhD}$ thesis was awarded to Dr. Dominik Kraus for his PhD-thesis work entitled:

\section{Characterization of phase transitions in hot dense matter with $\mathrm{X}$-ray scattering.}

Figure 1 shows the award ceremony

The experimental work was carried out at GSI using the laser systems nhelix and PHELIX.

Other young scientist ranging from young Post Docs to students who just finished their Master thesis received a special mentioning and these were:

P. Lang: Status of the PRIOR project;

M. Endres: Transport Coefficients in Non-ideal Plasma;

B. Ionita: Imaging interferometers for HEDP experiments at SIS18 and PHELIX at GSI-Darmstadt;

M. Povarnitsyn: Wide Range Model for Hydrodynamic Simulation of Laser Experiments;

B.R. Lee: VLF Signals Influenced by Meteorological Effects;
F. Wagner: Transport and Focusing of Laser-accelerated Protons;

M.M. Günther: Refractive Index of Silicon at Gamma- ray Energies.

Our journal Laser and Particle Beams will carry articles on these topics in the near future.

We wish the winners every success in their research work, moreover we want to encourage young scientists to submit their original research work to our journal and to compete for the Laser and Particle Beams Award.

Dieter H.H. Hoffmann Technische Universität Darmstadt, Institut für Kernphysik, Darmstadt, Germany Editor-in-Chief

\section{REFERENCE}

IFSA Conference 2013 in Nara, Japan. http://www.ifsa13.org/ about.html. 